Research Paper

\title{
Angiotensin-converting Enzyme Inhibitors Decrease the Incidence of Radiation-induced Pneumonitis Among Lung Cancer Patients: A Systematic Review and Meta-analysis
}

Fengze Sun ${ }^{1 \#, ~ H u a n h u a n ~ S u n}{ }^{1 \#}$, Xiaobin Zheng'2, Guangwei Yang1, Nana Gong', Huaili Zhou', Siyang Wang ${ }^{1}$, Zhibin Cheng ${ }^{1 凶}$, Haiqing Ma ${ }^{\circledR}$

1. Department of Oncology, The Fifth Affiliated Hospital of Sun Yat-Sen University, Zhuhai, Guangdong 519000, China

2. Department of Respiratory Medicine, The Fifth Affiliated Hospital of Sun Yat-Sen University, Zhuhai, Guangdong 519000, China

3. Department of Laboratory, The Fifth Affiliated Hospital of Sun Yat-Sen University, Zhuhai, Guangdong 519000, China

\#These authors have contributed equally to this work.

$\triangle$ Corresponding authors: Haiqing Ma, email: mahaiqing@mail.sysu.edu.cn and Zhibin Cheng, email: drczb@163.com

(C) Ivyspring International Publisher. This is an open access article distributed under the terms of the Creative Commons Attribution (CC BY-NC) license (https://creativecommons.org/licenses/by-nc/4.0/). See http://ivyspring.com/terms for full terms and conditions.

Received: 2017.12.31; Accepted: 2018.04.05; Published: 2018.05.25

\begin{abstract}
Background: Angiotensin-converting enzyme inhibitors (ACEls) and angiotensin receptor blockers (ARBs) have been demonstrated to mitigate radiation-induced lung damage in animal models and preclinical studies. Our study aims to evaluate whether ACEls or ARBs reduce the incidence of radiation-induced pneumonitis (RP) in lung cancer patients.

Methods: Publications were searched from EMBASE, PubMed and Web of Science databases. Seven studies published from April 2000 to August 2016 met inclusion criteria and included 1412 patients in total. Only patients with grade 2 and above pneumonitis within 12 months after radiotherapy were analyzed.

Results: Patients taking ACEls had a lower risk of developing radiation pneumonitis compared with non-users $(O R=0.46,95 \% \mathrm{Cl}=0.31-0.67, p<0.0001)$. While the use of ARBs couldn't reduce the incidence of $R P(O R=1.42,95 \% \mathrm{Cl}=0.94-2.14, p=0.10)$. Elderly patients (age $\geq 70$ ) benefited more from ACEls $(O R=0.12,95 \% \mathrm{Cl}=0.02-0.67, p=0.02)$. In addition, smokers were found to have a lower risk of developing RP than non-smokers $(\mathrm{OR}=0.49,95 \% \mathrm{Cl}=0.30-0.81, p=0.005)$, but sex and the use of statin or NSAID had no influence on the appearance of $\operatorname{RP}(p=0.59, p=0.70, p=$ 0.40 , respectively).

Conclusions: ACE inhibitors could decrease the incidence of symptomatic RP among lung cancer patients. However, the use of ARBs has a slight trend to develop RP but not above statistical significance. Elderly patients (age $\geq 70$ ) benefited the most from ACEls.
\end{abstract}

Key words: angiotensin-converting enzyme inhibitors; angiotensin receptor blockers; lung cancer; radiotherapy; radiation pneumonitis.

\section{Introduction}

Lung cancer accounts for the leading cause of death from cancer around the world. ${ }^{1}$ The morbidity of lung cancer remains high and most patients require radiotherapy. Thus, radiation-induced injury especially radiation pneumonitis (RP) is becoming a common problem, despite progress achieved in radiation planning and technique. Pneumonitis is the main dose-limiting toxicity encountered after radiotherapy. ${ }^{2}$ Symptomatic RP significantly reduces patients' quality of life and limits the therapeutic 
effect of radiation treatment. In recent years, scientists have gained new insights into the pathogenesis of RP.

Transforming growth factor $\beta$ (TGF- $\beta$ ), Tumor necrosis factor alpha (TNF- $\alpha$ ), IL-6, IL-8 and other cytokines play a vital role in the development of RP. . $^{3-6}$ TGF- $\beta$ is upregulated early and persistently in lung tissue damaged by radiation. ${ }^{7}$ The elevation of TGF- $\beta$ is highly associated with the risk of radiation pneumonitis. ${ }^{8}$ Regulating the levels of TGF- $\beta$ and other cytokines could provide effective prevention and treatment for RP. ACE inhibitors and ARBs are commonly used to treat hypertension and several cardiac diseases. ACE inhibitors and ARBs have been found to regulate TGF- $\beta$, VEGF and other cytokines which could decrease tissue damage and radiation necrosis, inhibit angiogenesis, attenuate tumor growth, and even improve survival of cancer patients.9-14 Similar protective effects have been demonstrated in animal models and preclinical trials. ${ }^{15-18}$ One clinical study reported either pre-RT or during-RT, ACE levels were significant lower in an $\mathrm{RP}$ group compared with a non-RP group, ${ }^{19}$ which means that lower plasma ACE is likely a risk factor for RP. In another study, Wang et al. ${ }^{20}$ concluded that neither ACEIs or ARBs could reduce the incidence or delay the appearance of symptomatic RP among lung cancer patients. In addition, randomized control trial NRG Oncology Radiation Therapy Oncology Group 0123 was aimed to test the ability of captopril to affect the incidence of pulmonary damage after radiotherapy, but this study closed early due to the low accrual. ${ }^{21}$

In recent years, articles regarding the role of ACEIs and ARBs in mitigating lung toxicity after radiation therapy have reached differing conclusions, so that the role of these two drugs in preventing RP remains unclear. Hence our study was designed to determine whether ACEIs or ARBs decrease the incidence of radiation induced pneumonitis among lung cancer patients.

\section{Material and Methods}

\section{Literature search}

We conducted our meta-analysis using PRISMA statement guidelines. ${ }^{22}$ Publications were searched from PubMed, EMBASE and Web of Science databases. Seven articles published from April 2000 to August 2016 met inclusion criteria and all were human trials. All patients from included studies have had lung computed tomography (CT) scan or 4-dimensional free-breathing CT scan or positron emission tomography (PET). RP was scored by the Common Terminology Criteria for Adverse Events v4.0 and was divided into 5 grades. ${ }^{23}$ For the requirements of our analysis, symptomatic RP was defined as grade 2 and above.

\section{Study selection and quality assessment}

In the experimental group, patients took either ACEIs or ARBs, while patients in the control group did not. Inclusion criteria were as follows: (1) Studies concerned lung cancer patients. (2) ACE inhibitors and/or ARBs were used. (3) Patients had received radiation therapy. (4) Only grade 2 or higher pneumonitis were included.

Exclusion criteria were as follows: (1) Studies did not involve lung cancer patients. (2) Patients did not take ACEIs or ARBs. (3) No active follow up (less than 12 months). (4) Systematic review with data absent.

Methodological quality of the included studies was evaluated by the Newcastle-Ottawa Scale (NOS) of nonrandomized studies. The NOS consisted of 3 parameters: selection, comparability and outcome with a maximum score of 9 . We defined studies with a score of 6 and above as high quality studies.

\section{Data extraction}

Two reviewers independently searched the potential relevant articles by scanning titles and eligible abstracts. Any disagreements were resolved by discussion with a third reviewer. Data extracted from all involved studies were summarized as follows: first author's last name, year of publication, age, number of patients, radiotherapy dose, follow up, incidence and number of RP in the experimental group and the control group.

\section{Statistical analysis}

We used Review Manager 5.3 software for statistical analysis and forest plots to show the results. ACEIs and ARBs were compared with each control group to estimate the odds ratios and $95 \%$ confidence intervals. A statistically significant difference was shown by $p<0.05$. For heterogeneity, an $I^{2}$ test was used to measure the variation among studies. The $I^{2}$ ranged from 0 to $100 \%$ according to the Cochrane Handbook for Systematic Review of Intervention Version 5.1.0 (0 to 40\%: the heterogeneity might be unimportant; 30 to $60 \%$ : might represent moderate heterogeneity; 50 to $90 \%$ : substantial heterogeneity exists; and 75 to $100 \%$, considerable heterogeneity). ${ }^{24}$ A fixed-effect model was used when $I^{2}$ was below $40 \%$, otherwise, a random effect model was used. We did sensitivity analysis to test the stability and reliability of the results. Publication bias was presented by Funnel plots and assessed by Egger's test. For Egger's test, $p>0.10$ was considered to mean no obvious publication bias. 


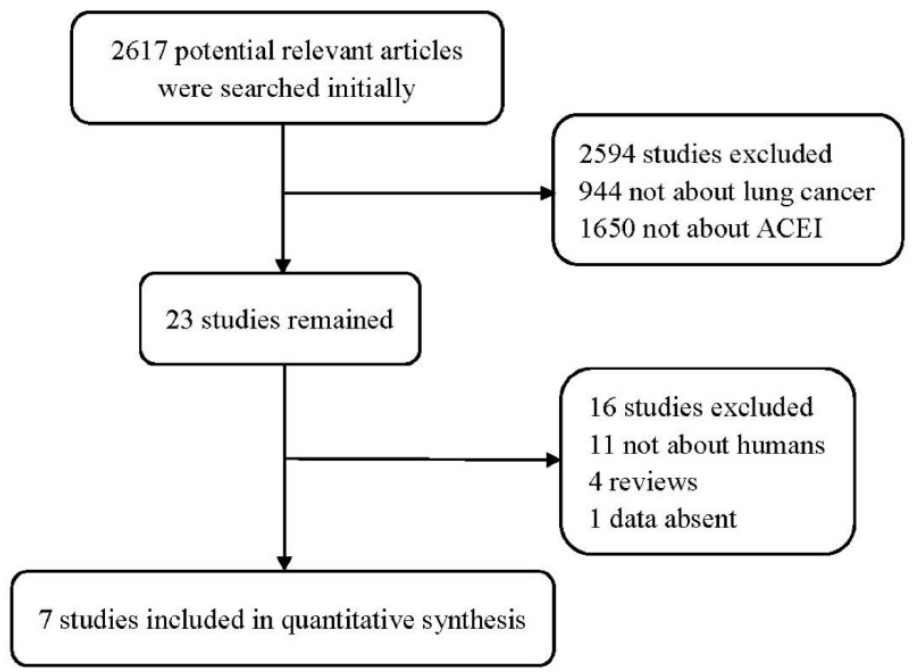

Figure 1. Flow diagram of the study selection process.

Table 1. Main characteristics of the included studies.

\begin{tabular}{|c|c|c|c|c|c|c|c|}
\hline \multirow[t]{2}{*}{ study } & \multirow[t]{2}{*}{ Median age } & \multirow[t]{2}{*}{ Median follow up (month) } & \multirow[t]{2}{*}{ Median dose or range(Gy) } & \multicolumn{2}{|l|}{ patients } & \multirow[t]{2}{*}{ total } & \multirow[t]{2}{*}{ NOS score } \\
\hline & & & & ACEI use & nonusers & & \\
\hline Bracci 2016 & 72 & 13.8 & 30 & 33 & 125 & 158 & 8 \\
\hline Wang 2013 & 66 & 18 & $\geq 60$ & 65 & 348 & 413 & 8 \\
\hline Alite 2016 & 71 & 24.8 & $48-60$ & 49 & 140 & 189 & 7 \\
\hline Kharofa 2012 & 65 & Not given & Not given & 62 & 100 & 162 & 7 \\
\hline Harder 2015 & 75 & $\geq 12$ & 54 & 70 & 187 & 257 & 8 \\
\hline Wang 2000 & 66 & 24 & $50-80$ & 26 & 187 & 213 & 8 \\
\hline Small 2016 & 65 & $>16$ & $\geq 45$ & 7 & 13 & 20 & - \\
\hline
\end{tabular}

Abbreviations: ACEI, angiotensin-converting enzyme inhibitor; NOS, the Newcastle-Ottawa Scale of cohort studies.

\section{Results}

\section{Search results}

Total of 2617 publications were searched initially. After irrelevant and duplicate papers were excluded, 23 studies remained. Then, 16 articles were abandoned for further reasons: 11 studies were animal studies rather than human; 4 were review articles; and data from 1 study was absent. After applying the inclusion and exclusion criteria, 7 studies including 1412 patients were included for analysis (Figure 1). Their main characteristics are summarized in Table 1.

\section{Quality assessment}

The results of quality assessment were evaluated by the NOS of cohort studies and presented in Supplementary Table S1. All included studies with a NOS score greater than 6 were determined as high quality studies. Most studies had a good representativeness except Kharofa et al. ${ }^{25}$ which included men only. There were no statements about adequacy of follow up in all included studies. All other factors met our requirements.

\section{Efficacy assessment}

In the ACEIs group, 39 of 312 patients developed RP compared with 285 of 1100 patients in the non-ACEIs group (12.5\% vs. $25.9 \%$ ). The use of ACE inhibitors showed a significant effect to reduce the risk of radiation-induced pneumonitis compared with the non-ACEIs group (OR $=0.46,95 \% \mathrm{CI}=0.31-0.67, p$ $<0.0001)$ and low heterogeneity was identified $\left(I^{2}=\right.$ $26 \%)$. However, 44 of 144 ARBs users developed RP compared with 250 of 1021 nonusers $(30.6 \%$ vs. $24.5 \%)$. ARBs not only failed to decrease the incidence of $\mathrm{RP}$, but also showed a slight trend to promote the appearance of RP, although the difference was not statistically significant $(\mathrm{OR}=1.42,95 \% \mathrm{CI}=0.94-2.14, p$ $=0.10$ ). Considering ACEIs and ARBs as a whole, this difference remained below statistical significance. (OR $=0.54,95 \% \mathrm{CI}=0.12-2.44, p=0.43$ ). (Figure 2). The results of freedom from symptomatic radiation pneumonitis (FFSRP) at 6 month and 12 month follow-ups are shown in Figure 3. At 6 months, the use of ACE inhibitors freed 141 of 144 (97.9\%) ACEI users of RP compared with 302 of 333 (90.7\%) nonusers $(p=0.01)$. At 12 months, 163 of $178(91.6 \%)$ ACEI users compared with 502 of $607(82.7 \%)$ nonusers were freed from RP $(p<0.0001)$. Both initially and long term, ACE inhibitors proved effective at decreasing the incidence of RP. 


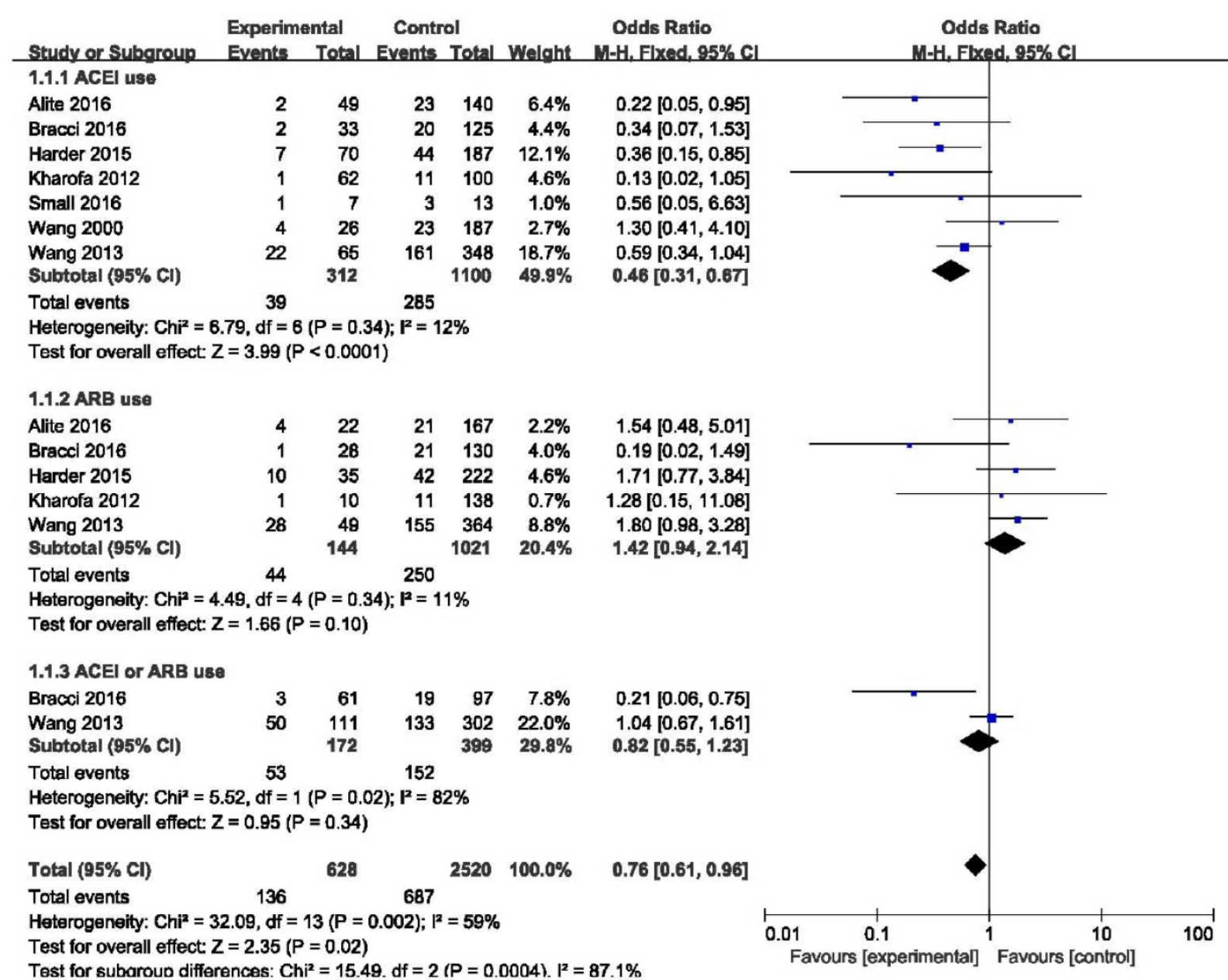

Figure 2. Forest plot of the use of ACEI, ARB, ACEI or ARB. Abbreviations: $\mathrm{Cl}$, confidence interval; OR, odds ratio; Event, radiation pneumonitis; $\mathrm{ACEl}$, angiotensin-converting enzyme inhibitor; ARB, angiotensin receptor blocker; ACEl or ARB, consider the use of ACEl and ARB as a whole.

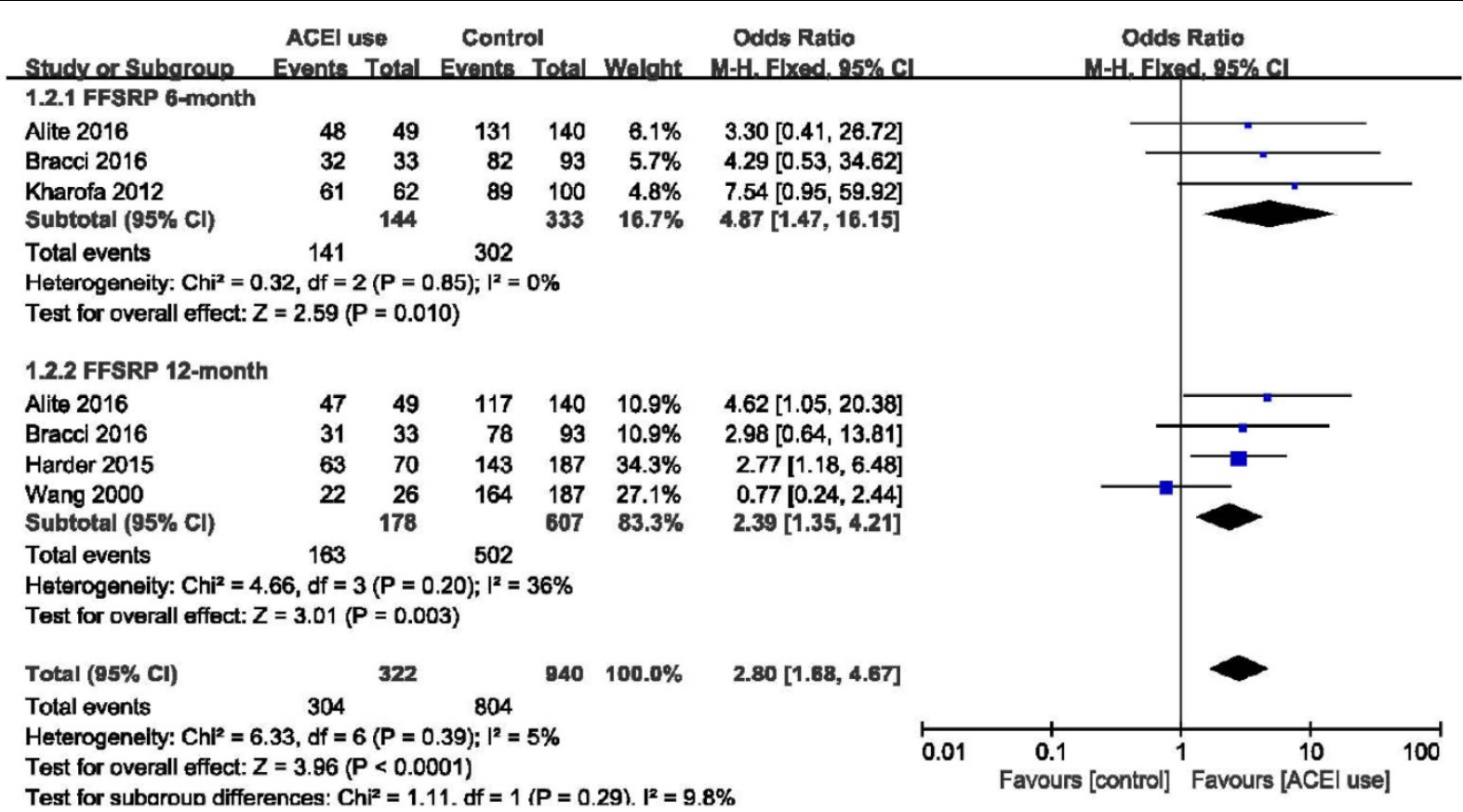

Figure 3. Forest plot of the odds ratio (OR) of FFSRP at 6 months and 12 months. Abbreviations: $\mathrm{Cl}$, confidence interval; OR, odds ratio; Event, radiation pneumonitis; ACEl, angiotensin-converting enzyme inhibitor; FFSRP, freedom from symptomatic radiation pneumonitis. 


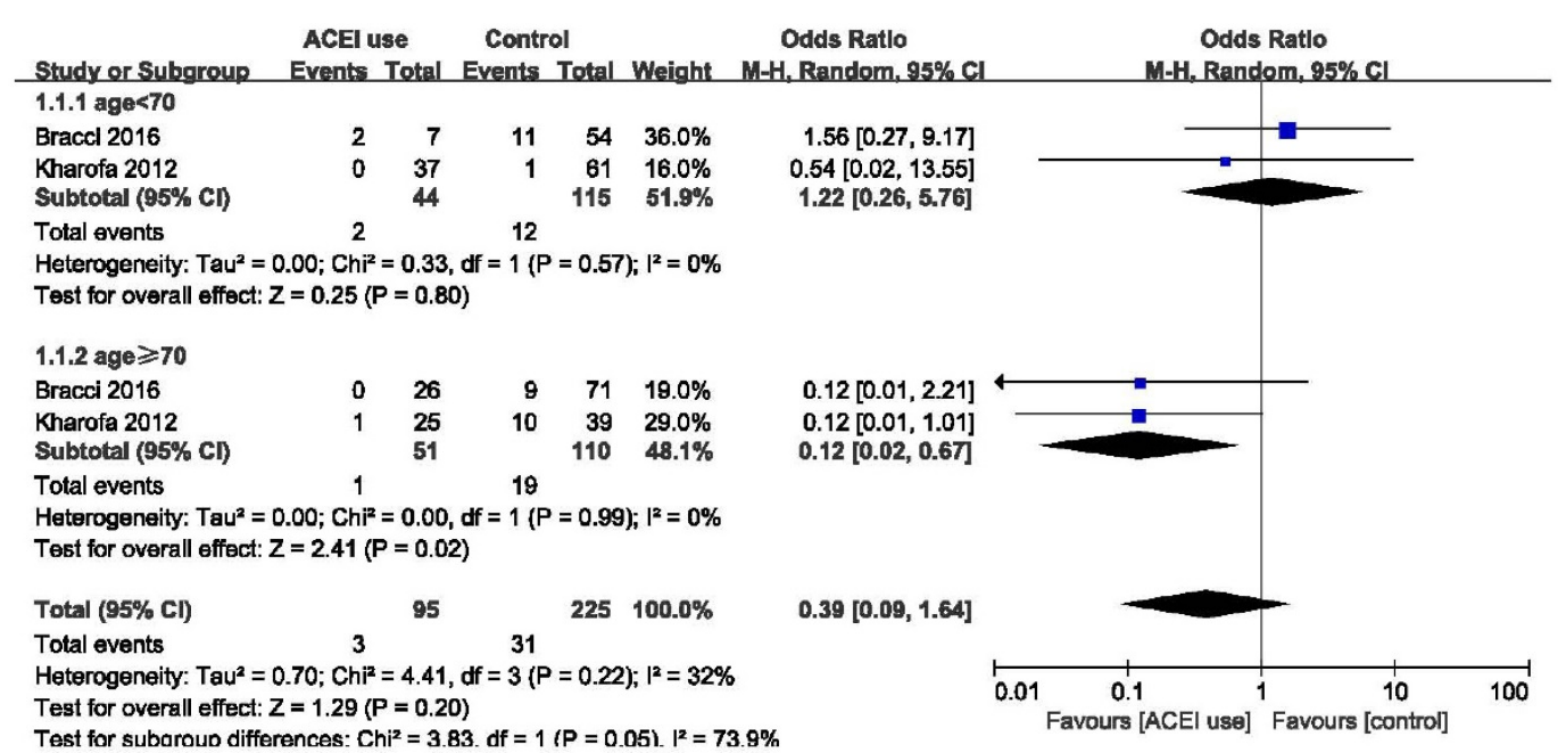

Figure 4. Forest plot of the comparison of age $<70$ and age $\geq 70$. Abbreviations: $\mathrm{Cl}$, confidence interval; OR, odds ratio; Event: radiation pneumonitis.

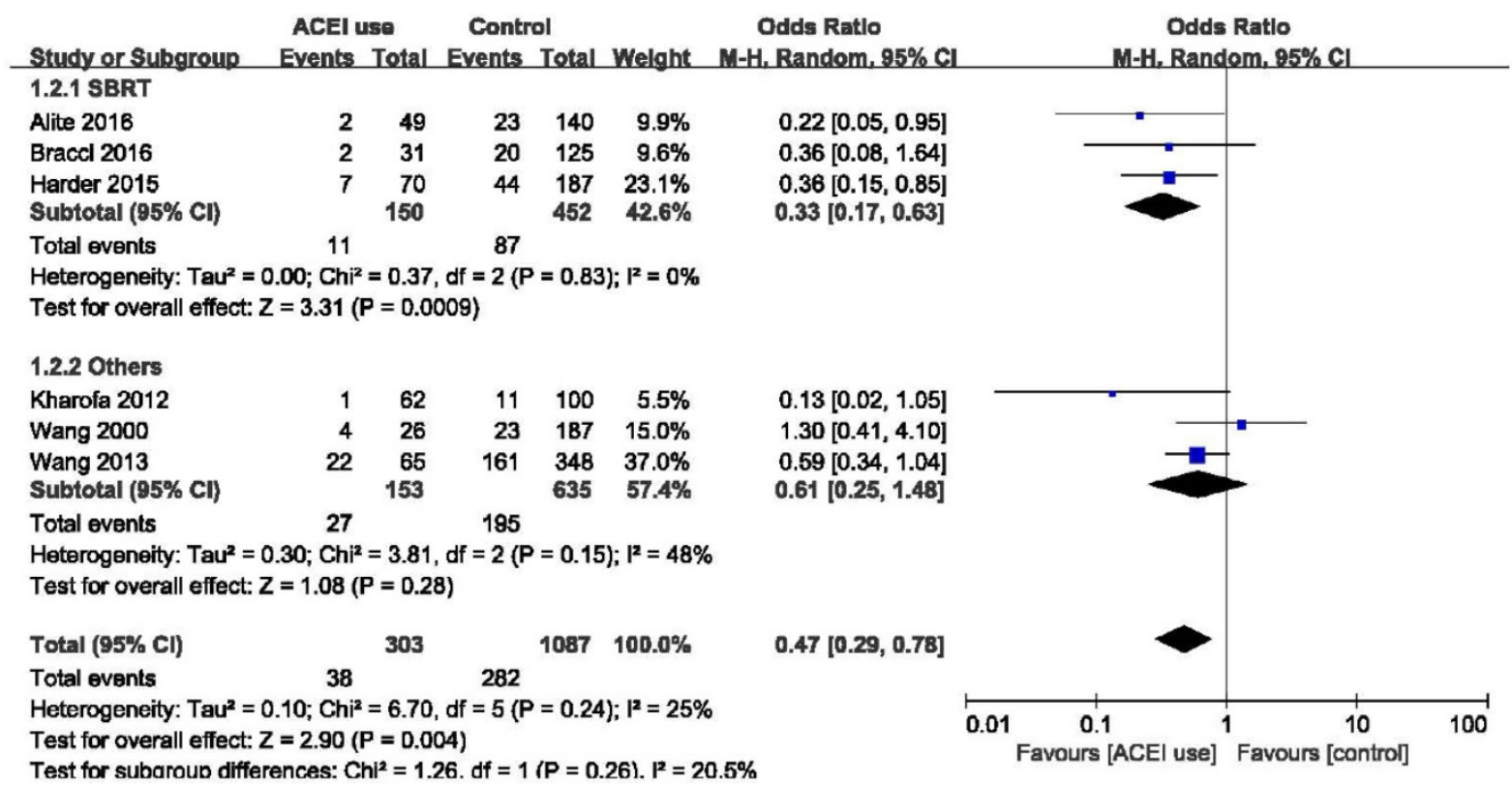

Figure 5. Forest plot of the comparison of SBRT and other radiation techniques. Abbreviations: $\mathrm{Cl}$, confidence interval; OR, odds ratio; Event, radiation pneumonitis; SBRT: Stereotactic body radiotherapy.

\section{Subgroup analysis}

Elderly patients are those most at risk of developing pneumonitis after radiation therapy. ${ }^{26}$ However, we found that elderly patients (age $\geq 70$ ) may benefit more from the use of ACE inhibitors (OR $=0.12,95 \% \mathrm{CI}=0.02-0.67, p=0.02)$ than patients age $<$ 70 years $(\mathrm{OR}=1.22,95 \% \mathrm{CI}=0.26-5.76, p=0.80)$, although the difference between these two group was only slightly statistically significant $(p=0.05)$ (Figure 4). Stereotactic body radiotherapy (SBRT) was reported to be more beneficial than $3 \mathrm{D}-\mathrm{CRT}$ or IMRT in treating early stage non-small cell lung cancer (NSCLC). In patients treated with SBRT, ACEIs were clearly effective as we demonstrated $(\mathrm{OR}=0.33$,
$95 \% \mathrm{CI}=0.17-0.63, p=0.0009)$. High heterogeneity existed in the group treated with other radiation techniques $\left(I^{2}=48 \%\right)$, and there was no obvious statistical significance in this group $(\mathrm{OR}=0.61,95 \% \mathrm{CI}$ $=0.25-1.48, p=0.28)$. And no statistical significance was found between these two groups $(p=0.26)$. In overall effect, ACEIs were effective for all patients regardless of the radiation technique they accepted $(\mathrm{OR}=0.47,95 \% \mathrm{CI}=0.29-0.78, p=0.004)$. (Figure 5). Sex, smoking status, and the use of statin and nonsteroidal anti-inflammatory drugs (NSAID) were abstracted from included studies to evaluate the relationship between radiation pneumonitis and these factors. We found that patients who smoked previously or currently had a lower risk of RP than 


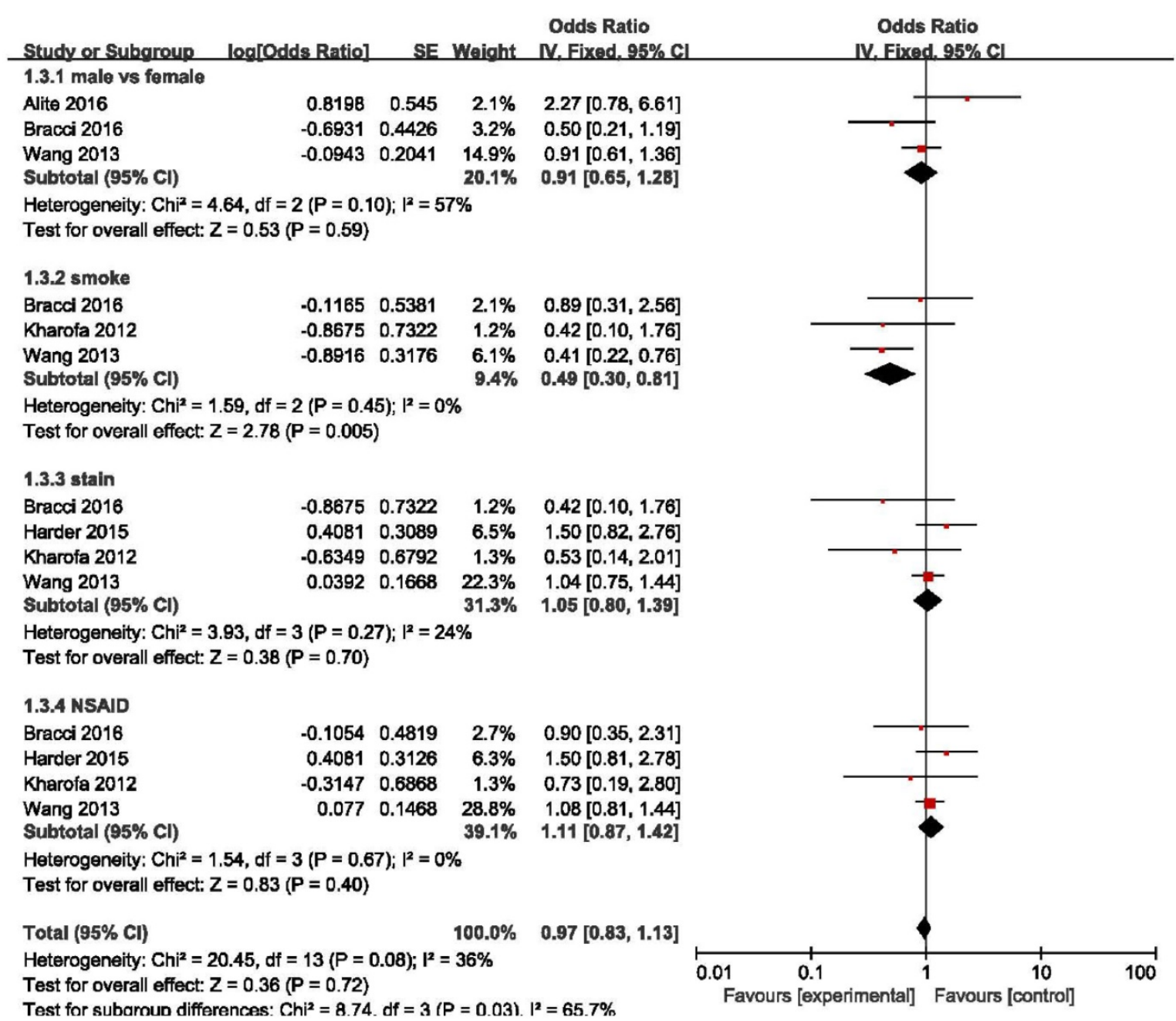

Figure 6. Forest plot of the $\log (\mathrm{OR})$ of sex, smoking status, use of statins and NSAIDs. Abbreviations: $\mathrm{Cl}$, confidence interval; NSAID, nonsteroidal Anti-inflammatory Drugs.

non-smokers $(\mathrm{OR}=0.49,95 \% \mathrm{CI}=0.30-0.81, p=0.005)$, but sex and the use of statin or NSAID had no influence on the appearance of RP ( $p=0.59, p=0.70, p$ $=0.40$, respectively). (Figure 6 ).

\section{Publication bias and sensitivity analysis}

Figure 7 shows the results of publication bias, which were evaluated by funnel plots and Egger's test. No obvious publication bias was identified (Egger's test: $p=0.225$ for analysis of ACEIs use). We observed that the overall results were still stable and reliable when each study was excluded or included, so that the sensitivity of our results was low.

\section{Discussion}

To our knowledge, this is the first meta-analysis to analyze the effect of ACEIs and ARBs in preventing radiation pneumonitis among lung cancer patients. Pertinent findings were summarized as follows. In our analysis, we found that the use of ACE inhibitors was associated with a significant reduction in the risk of radiation-induced pneumonitis among lung cancer patients $(p<0.0001)$, especially elderly patients. On the contrary, ARBs not only failed to reduce the incidence of RP, but have a slight trend to promote $\mathrm{RP}$, though the difference was not statistically significant. In addition, patients who have a smoking history or smoke currently have a lower risk than non-smokers for developing RP.

In the past few decades, radiation techniques have developed rapidly, including 3D-CRT, IMRT, IGRT, SBRT, proton and particle beam therapy ${ }^{27}$. But radiation- induced pneumonitis still cannot be completely prevented, which restricts the therapeutic dose and effectiveness of treatment. ACE inhibitors and ARBs have been demonstrated to help reduce the risk of RP among some animal models and preclinical trials. ${ }^{15,} 28$ ACEIs but not ARBs also proved useful for preventing pneumonia (but not radiation induced pneumonitis) in one analysis with a large number of patients. ${ }^{29}$ Whether ACEIs or ARBs could play a protective role in radiation-induced pneumonitis has remained controversial. 


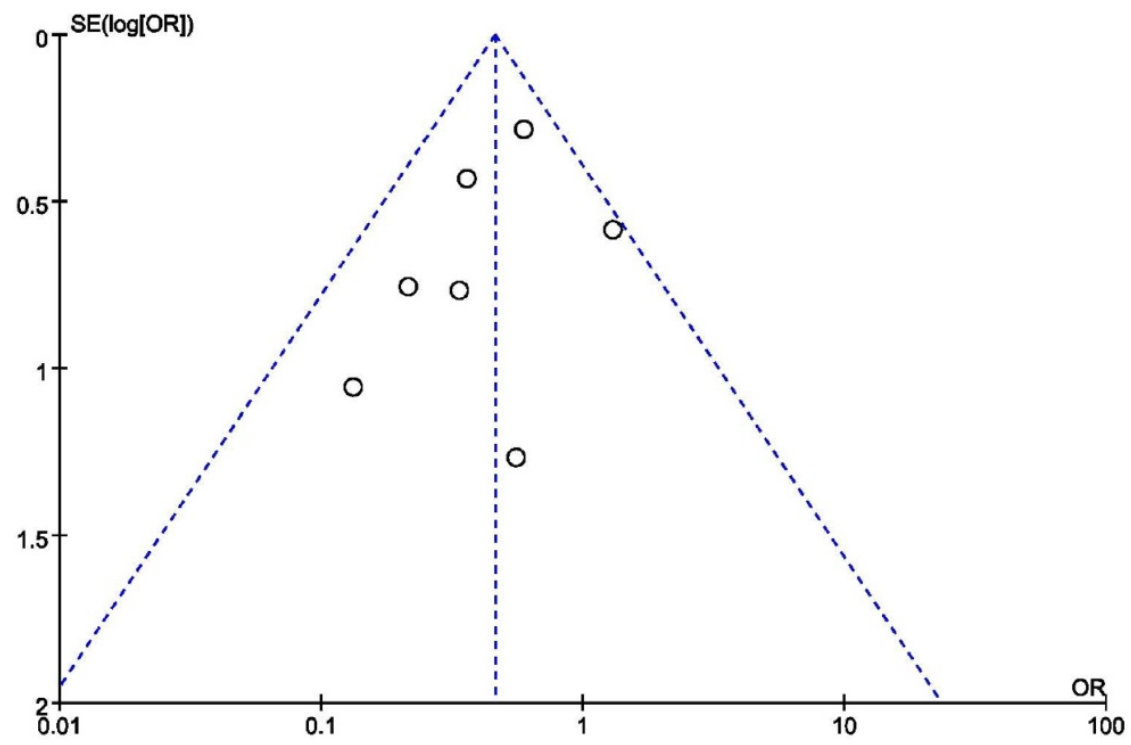

Figure 7. Funnel plot based on odds ratio.

Wang et al. ${ }^{20}$ reported a cohort study including 213 patients, but most patients were accepted with 2D non-conformal RT between 1994 and 1997, and no difference was found between the ACEIs group and non-users group $(15 \%$ vs. $12 \%, p=0.75)$. In our opinion, the low efficacy of ACEIs in this study may be associated with the imperfection of 2D-CRT and the high radiotherapy dose. Afterwards, Kharofa et al. ${ }^{25}$ reported a study with 162 patients who were treated with radiation from 2004 to 2009. The incidence of Grade $\geq 2$ pneumonitis was lower in ACEI users compared with non-users $(2 \%$ vs. $11 \%, p=$ $0.03)$, ARBs did not have this effect. Wang et al. ${ }^{30}$ retrospectively analyzed 413 patients of NSCLC treated with at least $60 \mathrm{~Gy}$ and found that the rate of grade $\geq 2 \mathrm{RP}$ was lower in ACEI users than non-users ( $34 \%$ vs. $46 \%$ ), although the apparent difference was not statistically significant $(p=0.06)$. After evaluating 189 patients with a median follow-up of 24.8 months, Alite et al. ${ }^{31}$ found a significant association between ACEI use and decreased risk of clinical pneumonitis. In another study, a total of 257 patients were included, and this study concluded that use of ACE inhibitors during SBRT was associated with significantly greater freedom from grade $\geq 2 \mathrm{RP}$ on univariate (vs nonusers, $89.8 \%$ vs. $76.3 \%$ at 12 months, $p=0.029)$ and multivariate analysis (hazard ratio $0.373,95 \% \mathrm{CI}=$ 0.156-0.891, $p=0.026) .{ }^{32}$ Consistent with Harder ${ }^{32}$, Bracci et al. ${ }^{33}$ demonstrated that ACE inhibitors were associated with a decreased incidence of RP after SBRT. However, they expressed different opinions in the effectiveness of ARBs for preventing RP. Bracci et al. combined ACEIs with ARBs groups into one group and concluded that RAS inhibitors were associated with a reduction of incidence for patients undergoing SBRT. There may be some biases because of the combination of ACEIs and ARBs. One clinical RCT of NRG Oncology Radiation Therapy Oncology Group 0123 was aimed to test the ability of the angiotensin-converting enzyme inhibitor captopril to alter radiation-induced pulmonary damage for lung cancer patients, but due to low accrual and a large number loss of patients, this study closed early. ${ }^{34}$ Only 20 patients were analyzed in this study, so that it is failed to evaluate patients' quality of life who have taken ACEIs and the long-term effects of captopril. The length and frequency of the medication may need to be improved, but this study did show the safety of the use of ACEIs among lung cancer patients who received radiotherapy. The results of our study suggested that ACEIs were useful for preventing RP, but ARBs were not. Whether in the short term or long term, ACE inhibitors had a significantly protective effect.

SBRT delivers a high radiation dose to the tumor so that a high local control rate is achieved. ${ }^{35,36}$ SBRT is the best choice for inoperable early stage NSCLC currently and may be preferable to surgery. ${ }^{37,} 38$ In subgroup analysis, we did not find a statistical difference between SBRT and other radiation techniques using ACE inhibitors. High heterogeneity was identified in the other radiation techniques group. When the data of patients treated with SBRT were analyzed specifically, ACEIs was shown to be effective rather than ARBs, and the difference was slightly above statistical significance. However, since the radiation therapy dose, range of $V_{20}$, and technique was highly variable among these studies, the strength of this subgroup analysis was a little weakened and should be evaluated by be verified by further studies. 
As well as its overall effect, the morbidity of RP was significantly reduced in elder patients who took ACEIs compared with non-users. Older age was considered as a risk factor of pulmonary toxicity for patients treated with thoracic radiation. ${ }^{39}, 40$ And elderly patients were observed to have an increased risk of symptomatic pneumonitis after radiotherapy. 26 Notably, we found that elderly patients could benefit more from ACE inhibitors than younger patients. This does not mean that younger patients do not benefit from ACE inhibitors; after all, the overall effect suggests a protective effect of ACEIs to prevent $\mathrm{RP}$ for the majority of patients.

Interestingly, we found that patients who have a smoking history or smoke currently have a lower risk than non-smokers for developing RP. Consistent with our result, Palma et al. ${ }^{41}$ reported that smokers have a protective effect on radiation pneumonitis ( $\mathrm{OR}=0.39$, $95 \% \mathrm{CI}=0.19-0.80, p=0.01)$. The protection mechanism of smoking in preventing RP remains unclear, but further studies may help to determine this. Bjermer et al. ${ }^{42}$ found that smokers displayed a weaker inflammatory reaction than non-smokers, possibly due to lower levels of lymphocytes and mast cells. Furthermore, radiation would undoubtedly injure the normal structure of DNA, and the repair state would affect the injury of tissues. The polymorphisms of DNA repair genes may play a different role based on smoking status. XRCC1 and ERCC2 are two DNA repair genes, and polymorphisms of these two genes are considered as a risk in non-smokers but have a protective effect in smokers. ${ }^{43}$ This may be due to the fact that polymorphisms of these repair genes were overwhelmed in heavy smokers. ${ }^{4}$

Several limitations exist in our study. First, there were only one clinical randomized controlled trial and most included studies were cohort studies, it limited the result to evaluate the effect of ACEIs or ARBs for mitigating the toxicity or reducing the incidence of radiation-induced pneumonitis. Second, the data we analyzed were extracted from published articles rather than original records. Due to some data being absent and the different range of $V_{20}$ and MLD in their papers, such as overall survival and the known factors of RP, chemotherapy and $V_{20}$, cannot be analyzed. Furthermore, as only 7 studies met our inclusion criteria, safety and efficacy should be verified by further studies. In the future, we will continue to explore these questions.

Our meta-analysis demonstrated that the use of ACEIs but not ARBs effectively reduced the incidence of radiation pneumonitis for most lung cancer patients. That has important clinical implications. Lung cancer patients accepting thoracic radiation could take an appropriate dose of ACEIs to prevent $\mathrm{RP}$ during or after the period of radiotherapy, which would greatly improve quality of life and therapeutic effect. By contrast, the more expensive ARBs are ineffective for preventing RP. Whether ARBs could promote the appearance of RP should be tested cautiously. For elderly lung cancer patients, ACEIs may help them to avoid radiation pneumonitis after radiotherapy, but we cannot neglect the specific conditions and potential adverse effects of ACEIs. We hope our results help pave the way for using ACE inhibitors to decrease the incidence of RP in future clinical trials and will inspire further research into preventing radiation induced inflammation in other organs.

\section{Supplementary Material}

Supplementary table.

http://www.jcancer.org/v09p2123s1.pdf

\section{Acknowledgements}

This research was supported by the National Natural Science Foundation of China (81500030) and the Natural Science Foundation of Guangdong Province (2016A030313272, 2016A030313277 and 2017A030313573).

\section{Competing Interests}

The authors have declared that no competing interest exists.

\section{References}

1. Siegel RL, Miller KD, Jemal A. Cancer Statistics, 2017. CA: a cancer journal for clinicians 2017;67: 7-30.

2. Jenkins P, Watts J. An improved model for predicting radiation pneumonitis incorporating clinical and dosimetric variables. International journal of radiation oncology, biology, physics 2011;80: 1023-9.

3. Rube CE, Wilfert F, Uthe D, Schmid KW, Knoop R, Willich N, Schuck A, Rube C. Modulation of radiation-induced tumour necrosis factor alpha (TNF-alpha) expression in the lung tissue by pentoxifylline. Radiotherapy and oncology: journal of the European Society for Therapeutic Radiology and Oncology 2002;64: 177-87.

4. Anscher MS, Kong FM, Marks LB, Bentel GC, Jirtle RL. Changes in plasma transforming growth factor beta during radiotherapy and the risk of symptomatic radiation-induced pneumonitis. International journal of radiation oncology, biology, physics 1997;37: 253-8.

5. Kainthola A, Haritwal T, Tiwari M, Gupta N, Parvez S, Tiwari M, Prakash H, Agrawala PK. Immunological Aspect of Radiation-Induced Pneumonitis, Current Treatment Strategies, and Future Prospects. Frontiers in immunology 2017;8: 506.

6. Wang S, Campbell J, Stenmark MH, Zhao J, Stanton P, Matuszak MM, Ten Haken RK, Kong FS. Plasma Levels of IL-8 and TGF-beta1 Predict Radiation-Induced Lung Toxicity in Non-Small Cell Lung Cancer: A Validation Study. International journal of radiation oncology, biology, physics 2017;98: 615-21.

7. Rubin P, Johnston CJ, Williams JP, McDonald S, Finkelstein JN. A perpetual cascade of cytokines postirradiation leads to pulmonary fibrosis. International journal of radiation oncology, biology, physics 1995;33: 99-109.

8. Liu Y, Xia T, Zhang W, Zhong Y, Zhang L, Wang X, Yu H. Variations of circulating endothelial progenitor cells and transforming growth factor-beta-1 (TGF-beta1) during thoracic radiotherapy are predictive for radiation pneumonitis. Radiation oncology 2013;8: 189.

9. Molteni A, Moulder JE, Cohen EF, Ward WF, Fish BL, Taylor JM, Wolfe LF, Brizio-Molteni L, Veno P. Control of radiation-induced pneumopathy and lung fibrosis by angiotensin-converting enzyme inhibitors and an angiotensin II type 1 receptor blocker. International journal of radiation biology 2000;76: 523-32. 
10. Molteni A, Wolfe LF, Ward WF, Ts'ao CH, Molteni LB, Veno P, Fish BL, Taylor JM, Quintanilla N, Herndon B, Moulder JE. Effect of an angiotensin II receptor blocker and two angiotensin converting enzyme inhibitors on transforming growth factor-beta (TGF-beta) and alpha-actomyosin (alpha SMA), important mediators of radiation-induced pneumopathy and lung fibrosis. Current pharmaceutical design 2007;13: 1307-16.

11. Chowdhary M, Okwan-Duodu D, Switchenko JM, Press RH, Jhaveri J, Buchwald ZS, Zhong J, Chapman BV, Bindra RS, Contessa JN, Park HS, Yu JB, et al. Angiotensin receptor blockade: a novel approach for symptomatic radiation necrosis after stereotactic radiosurgery. Journal of neuro-oncology 2018;136: 289-98.

12. Morris ZS, Saha S, Magnuson WJ, Morris BA, Borkenhagen JF, Ching A, Hirose G, McMurry V, Francis DM, Harari PM, Chappell R, Tsuji S, et al. Increased tumor response to neoadjuvant therapy among rectal cancer patients taking angiotensin-converting enzyme inhibitors or angiotensin receptor blockers. Cancer 2016;122: 2487-95.

13. Liu $H$, Naxerova $K$, Pinter $M$, Incio J, Lee $H$, Shigeta $K$, Ho WW, Crain JA, Jacobson A, Michelakos T, Dias-Santos D, Zanconato A, et al. Use of Angiotensin System Inhibitors Is Associated with Immune Activation and Longer Survival in Nonmetastatic Pancreatic Ductal Adenocarcinoma. Clinical cancer research: an official journal of the American Association for Cancer Research 2017;23: 5959-69.

14. Shrestha S, Noh JM, Kim SY, Ham HY, Kim YJ, Yun YJ, Kim MJ, Kwon MS, Song DK, Hong CW. Angiotensin converting enzyme inhibitors and angiotensin II receptor antagonist attenuate tumor growth via polarization of neutrophils toward an antitumor phenotype. Oncoimmunology 2016;5: e1067744.

15. Ghosh SN, Zhang R, Fish BL, Semenenko VA, Li XA, Moulder JE, Jacobs ER, Medhora M. Renin-Angiotensin system suppression mitigates experimental radiation pneumonitis. International journal of radiation oncology, biology, physics 2009;75: 1528-36.

16. Shah S, McArthur E, Farag A, Nartey M, Fleet JL, Knoll GA, Kim SJ, Garg AX, Jain AK. Risk of hospitalization for community acquired pneumonia with renin-angiotensin blockade in elderly patients: a population-based study. PloS one 2014;9: e110165.

17. Kma L, Gao F, Fish BL, Moulder JE, Jacobs ER, Medhora M. Angiotensin converting enzyme inhibitors mitigate collagen synthesis induced by a single dose of radiation to the whole thorax Journal of radiation research 2012:53: 10-7.

18. Mahmood J, Jelveh S, Zaidi A, Doctrow SR, Medhora M, Hill RP. Targeting the Renin-angiotensin system combined with an antioxidant is highly effective in mitigating radiation-induced lung damage. International journal of radiation oncology, biology, physics 2014;89: 722-8.

19. Zhao L, Wang L, Ji W, Wang X, Zhu X, Feng Q, Yang W, Yin W. Association between plasma angiotensin-converting enzyme level and radiation pneumonitis. Cytokine 2007;37: 71-5.

20. Wang LW, Fu XL, Clough R, Sibley G, Fan M, Bentel GC, Marks LB, Anscher MS. Can angiotensin-converting enzyme inhibitors protect against symptomatic radiation pneumonitis? Radiation research 2000;153: 405-10.

21. Small W, Jr., James JL, Moore TD, Fintel DJ, Lutz ST, Movsas B, Suntharalingam M, Garces YI, Ivker R, Moulder J, Pugh S, Berk LB. Utility of the ACE Inhibitor Captopril in Mitigating Radiation-associated Pulmonary Toxicity in Lung Cancer: Results From NRG Oncology RTOG 0123. American journal of clinical oncology 2016.

22. Liberati A, Altman DG, Tetzlaff J, Mulrow C, Gotzsche PC, Ioannidis JP, Clarke M, Devereaux PI, Kleijnen J, Moher D. The PRISMA statement for reporting systematic reviews and meta-analyses of studies that evaluate healthcare interventions: explanation and elaboration. Bmj 2009;339: b2700.

23. Institute NC. Common Terminology Criteria for Adverse Events, version 4.0. Washington, DC: US Department of Health and Human Services, National Institutes of Health, and National Cancer Institutes 2009.

24. Higgins JPT GS. Cochrane Handbook for Systematic Review of Interventions Version 5.1.0. 2011

25. Kharofa J, Cohen EP, Tomic R, Xiang Q, Gore E. Decreased risk of radiation pneumonitis with incidental concurrent use of angiotensin-converting enzyme inhibitors and thoracic radiation therapy. International journal of radiation oncology, biology, physics 2012;84: 238-43.

26. Kharofa J, Gore E. Symptomatic radiation pneumonitis in elderly patients receiving thoracic irradiation. Clinical lung cancer 2013;14: 283-7.

27. Wagner $\mathrm{H}$. Image-guided conformal radiation therapy planning and delivery for non-small-cell lung cancer. Cancer control: journal of the Moffitt Cancer Center 2003;10: 277-88.

28. Medhora M, Gao F, Jacobs ER, Moulder JE. Radiation damage to the lung: mitigation by angiotensin-converting enzyme (ACE) inhibitors. Respirology 2012;17: 66-71.

29. Caldeira D, Alarcao J, Vaz-Carneiro A, Costa J. Risk of pneumonia associated with use of angiotensin converting enzyme inhibitors and angiotensin receptor blockers: systematic review and meta-analysis. Bmj 2012;345: e4260.

30. Wang H, Liao Z, Zhuang Y, Xu T, Nguyen QN, Levy LB, O'Reilly M, Gold KA, Gomez DR. Do angiotensin-converting enzyme inhibitors reduce the risk of symptomatic radiation pneumonitis in patients with non-small cell lung cancer after definitive radiation therapy? Analysis of a single-institution database. International journal of radiation oncology, biology, physics 2013;87: 1071-7.

31. Alite F, Balasubramanian N, Adams W, Surucu M, Mescioglu I, Harkenrider MM. Decreased Risk of Radiation Pneumonitis With Coincident Concurrent
Use of Angiotensin-converting Enzyme Inhibitors in Patients Receiving Lung Stereotactic Body Radiation Therapy. American journal of clinical oncology 2016.

32. Harder EM, Park HS, Nath SK, Mancini BR, Decker RH. Angiotensin-converting enzyme inhibitors decrease the risk of radiation pneumonitis after stereotactic body radiation therapy. Practical radiation oncology 2015;5: e643-9.

33. Bracci S, Valeriani M, Agolli L, De Sanctis V, Maurizi Enrici R, Osti MF. Renin-Angiotensin System Inhibitors Might Help to Reduce the Development of Symptomatic Radiation Pneumonitis After Stereotactic Body Radiotherapy for Lung Cancer. Clinical lung cancer 2016;17: 189-97.

34. Small W, Jr., James JL, Moore TD, Fintel DJ, Lutz ST, Movsas B, Suntharalingam M, Garces YI, Ivker R, Moulder J, Pugh S, Berk LB. Utility of the ACE Inhibitor Captopril in Mitigating Radiation-associated Pulmonary Toxicity in Lung Cancer: Results From NRG Oncology RTOG 0123. American journal of clinical oncology 2018;41: 396-401.

35. Lagerwaard FJ, Haasbeek CJ, Smit EF, Slotman BJ, Senan S. Outcomes of risk-adapted fractionated stereotactic radiotherapy for stage I non-small-cell lung cancer. International journal of radiation oncology, biology, physics 2008;70: 685-92.

36. Guckenberger M, Wulf J, Mueller G, Krieger T, Baier K, Gabor M, Richter A, Wilbert J, Flentje M. Dose-response relationship for image-guided stereotactic body radiotherapy of pulmonary tumors: relevance of $4 \mathrm{D}$ dose calculation. International journal of radiation oncology, biology, physics 2009;74: 47-54.

37. Crabtree TD, Denlinger CE, Meyers BF, El Naqa I, Zoole J, Krupnick AS, Kreisel D, Patterson GA, Bradley JD. Stereotactic body radiation therapy versus surgical resection for stage I non-small cell lung cancer. The Journal of thoracic and cardiovascular surgery 2010;140: 377-86.

38. Baumann P, Nyman J, Hoyer M, Wennberg B, Gagliardi G, Lax I, Drugge N, Ekberg L, Friesland S, Johansson KA, Lund JA, Morhed E, et al. Outcome in a prospective phase II trial of medically inoperable stage I non-small-cell lung cancer patients treated with stereotactic body radiotherapy. Journal of clinical oncology: official journal of the American Society of Clinical Oncology 2009;27: 3290-6.

39. Schild SE, Stella PJ, Geyer SM, Bonner JA, McGinnis WL, Mailliard JA, Brindle J, Jatoi A, Jett JR, North Central Cancer Treatment G. The outcome of combined-modality therapy for stage III non-small-cell lung cancer in the elderly. Journal of clinical oncology: official journal of the American Society of Clinical Oncology 2003;21: 3201-6.

40. Shirvani SM, Jiang J, Chang JY, Welsh JW, Gomez DR, Swisher S, Buchholz TA, Smith BD. Comparative effectiveness of 5 treatment strategies for early-stage non-small cell lung cancer in the elderly. International journal of radiation oncology, biology, physics 2012;84: 1060-70.

41. Palma DA, Senan S, Tsujino K, Barriger RB, Rengan R, Moreno M, Bradley JD, Kim TH, Ramella S, Marks LB, De Petris L, Stitt L, et al. Predicting radiation pneumonitis after chemoradiation therapy for lung cancer: an international individual patient data meta-analysis. International journal of radiation oncology, biology, physics 2013;85: 444-50.

42. Bjermer L, Franzen L, Littbrand $B$, Nilsson $K$, Angstrom $T$, Henriksson $R$. Effects of smoking and irradiated volume on inflammatory response in the lung of irradiated breast cancer patients evaluated with bronchoalveolar lavage. Cancer research 1990;50: 2027-30.

43. Zhou W, Liu G, Miller DP, Thurston SW, Xu LL, Wain JC, Lynch TJ, Su L, Christiani DC. Polymorphisms in the DNA repair genes XRCC1 and ERCC2, smoking, and lung cancer risk. Cancer epidemiology, biomarkers $\mathcal{E}$ prevention: a publication of the American Association for Cancer Research, cosponsored by the American Society of Preventive Oncology 2003;12: 359-65.

44. Sun S, Schiller JH, Gazdar AF. Lung cancer in never smokers--a different disease. Nature reviews Cancer 2007:7: 778-90. 